Int. J. Dev. Biol. 56: 675-680 (2012)

doi: $10.1387 / \mathrm{ijdb} .1200291 \mathrm{~s}$

\title{
Relationship between brassinosteroids and genes controlling stomatal production in the Arabidopsis hypocotyl
}

\author{
SONIA FUENTES, ROBERTO C. CAÑAMERO and LAURA SERNA* \\ Facultad de Ciencias del Medio Ambiente y Bioquímica, Universidad de Castilla-La Mancha, Toledo, Spain
}

\begin{abstract}
Stomata are excellent model systems for examining the mechanisms that regulate cell fate determination and pattern formation. It has recently been demonstrated that brassinosteroids control stomatal development by regulating both the MAPK kinase kinase YODA and the basic helix-loop-helix transcriptional factor SPEECHLESS. Here, we show that these plant regulators positively regulate stomatal formation in the hypocotyl and also accelerate their development. Hormone tests, reporter gene studies and mutant analyses revealed that brassinosteroids act upstream of the transcriptional factors CAPRICE and GLABRA2. These plant regulators control an earlier stage of stomatal production than those regulated by the membrane receptor TOO MANY MOUTHS. This work highlights differences in the genetic control of stomatal development between cotyledons or leaves and hypocotyls.
\end{abstract}

KEY WORDS: Arabidopsis thaliana, brassinosteroids, CAPRICE, GLABRA2, stomata

\section{Introduction}

The plant epidermis provides an elegant model system that allows exploration of the mechanisms that regulate cell fate specification and patterning formation. In particular, the hypocotyl epidermis of Arabidopsis thaliana offers an excellent model system because of its rapid development and simplicity. It reaches maturity one week after germination and consists of two types of files that run parallel to the long axis of the organ (Gendreau et al., 1997; Berger et al., 1998). These include files consisting of non-protruding cells and located outside two cortical cell files, and files consisting of protruding cells that overlie a single cortical cell file. Stomata develop only in epidermal files located outside two cortical cell files (Berger et al., 1998; Hung et al., 1998). The first sign of stomatal development is a cell division along its longitudinal axis producing a small and often triangular or rectangular cell named meristemoid (Berger et al., 1998), which makes stomatal pathway initiation easy to detect. Meristemoids are self-renewing cells that undergo a probabilistic sequence of cell divisions before stomata formation (Berger et al., 1998).

Molecular genetic studies have defined a number of genes that influence stomata formation and patterning in the embryonic stem. The GLABRA2(GL2) gene, which encodes a homeodomainleucine zipper protein (Rerie et al., 1994; Di Cristina et al., 1996), negatively regulates stomata formation in cell files located outside a single cortical cell file (Berger et al., 1998; Hung et al., 1998).
TRANSPARENT TESTA GLABRA (TTG) encodes a small protein with WD40 repeats (Walker et al., 1999), and also represses the formation of ectopic stomata (Rerie et al., 1994; Hung et al., 1998). The WEREWOLF (WER) gene negatively regulates stomatal cell fate (Lee and Schiefelbein, 1999). WER encodes a R2R3MYB protein that, like GL2(Hung et al., 1998), is preferentially expressed in epidermal cell files located outside a single cortical cell file (Lee and Schiefelbein, 1999). The TTG expression pattern remains unknown. Yeast two-hybrid assays have shown that both TTG and WER proteins physically associate with two BHLH proteins GLABRA3 (GL3) and ENHANCER OF GLABRA3 (EGL3) (Payne et al., 2000; Bernhardt et al., 2003; Zhang et al., 2003). These $\mathrm{BHLH}$ genes redundantly repress the formation of stomata in files overlying a single cortical cell file (Bernhardt et al., 2005). Moreover, TTG and WER are positive regulators of the GL2 gene (Hung et al., 1998; Lee and Schiefelbein, 1999).

In addition to these repressors of stomata formation, positive regulators have been identified. CAPRICE $(C P C)$ and TRIPTY CHON (TRY), both encoding R3MYB proteins (Wada et al., 1997; Schellmann et al., 2002), redundantly promote stomatal formation (Serna, 2008). Like WER and GL2, CPC (and probably TRY) is expressed in files characterized by an absence of stomata (Kirik et al., 2004; Serna, 2008). CPC (and probably TRY) moves to

Abbreviations used in this paper: BL, epibrassinolide; CPC, CAPRICE; GL2, GLABRA2; TAF, triadimefon; TMM, TOO MANY MOUTHS.

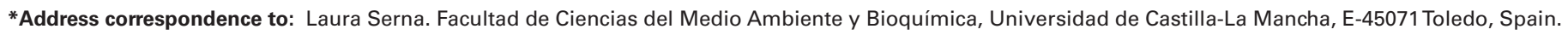
Tel: +34-925-26-8800. Fax: +34-925-26-8840. e-mail: laura.serna@uclm.es
} 
stomata-forming cell files where it then acts (Serna, 2008). Like WER, CPC and TRY also associate with both GL3 and EGL3 (Zhang et al., 2003). These findings support the inference that a multimeric complex consisting of WER, TTG, GL3, and/or EGL3 represses stomata formation by promoting GL2 transcription in epidermal cell files overlying a single cortical cell file (Larkin et al., 2003; Schiefelbein, 2003; Serna, 2004a; Serna, 2004b). Both stomata development and GL2 expression repression in epidermal cell files located above two cortical cell files depend on the sequestration of GL3 and EGL3 by CPC (and/or TRY), inducing the formation of a complex consisting of CPC (and/or TRY), TTG, GL3, and/or EGL3 (Serna, 2008). CPC and TRY are not the only positive regulators of stomatal cell fate in the embryonic stem. The TOO MANY MOUTHS (TMM) gene, which encodes a leucin-rich repeat receptor-like protein without a cytoplasmic domain (Nadeau and Sack, 2002), also promotes stomatal formation (Geisler et al., 1998). This gene controls stomatal progression from meristemoids, but is not essential for entry into the stomatal pathway (Bhave et al., 2009).

It is known that the regulation of stomatal formation in the hypocotyl is controlled by hormones. Stomata development is induced by gibberellins (Saibo et al., 2003). Furthermore, the effect of gibberellins is enhanced by ethylene and auxins (Saibo et al., 2003). In addition, brassinosteroids control stomatal development by regulating both the MAPK kinase kinase YODA and the basic helix-loop-helix transcriptional factor SPEECHLESS (Kim et al., 2012; Gudesblat et al., 2012). Analysis of global transcriptome of Arabidopsis seedlings has shown that brassinosteroids induce WER expression (Nemhauser et al., 2004), which suggests some relationship between these plant regulators and genes controlling stomatal production. Here, we explore the role of brassinosteroids in stomatal development in the hypocotyl, and their hypothetical interactions with genes regulating this process.

\section{Results}

Brassinosteroids promote stomatal formation in the hypocotyl

Plants treated with $0.5 \mu \mathrm{M}$ epibrassinolide exhibited a statistically significant increase in number of stomata on the hypocotyl relative to untreated plants (Table 1). Plants treated with $1 \mu \mathrm{M}$ triadimefon, which inhibits biosynthesis of brassinosteroids and gibberellins (Buchenauer and Rohner, 1981; Asami et al., 2003), showed a small reduction in the number of stomata, with the exception of Col-0 (Table 1). This reduction was counteracted by
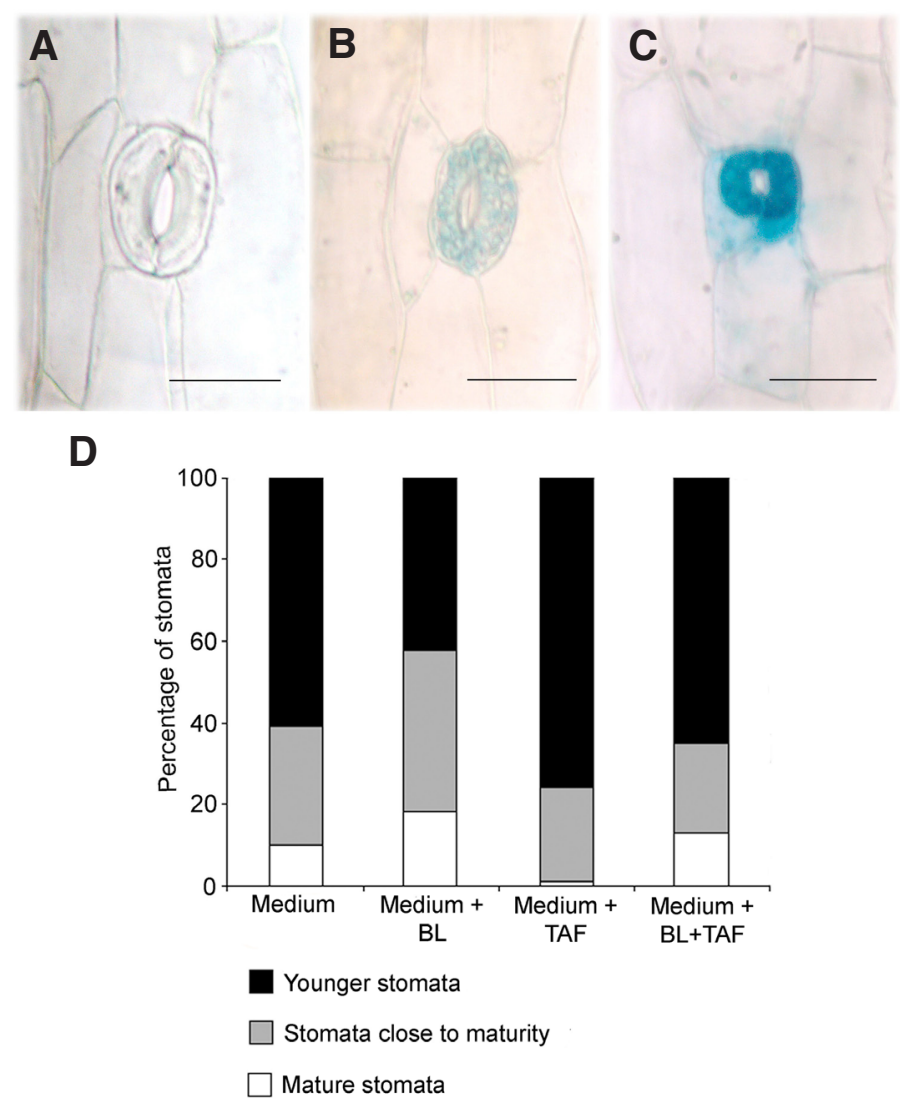

Fig. 1. Stomatal maturation and TMM (TOO MANY MOUTHS) expression in response to brassinosteroids. (A-C) Transgenic plants expressing GUS under control of the TMM showing (A) mature stomata, (B) stomata closer to maturity and (C) younger stomata. (D) Effect of brassinosteroids on stomatal maturation. BL, epibrassinolide; TAF, triadimefon. Scale bars: $20 \mu \mathrm{m}$ in $(A-C)$.

the co-application of $0.5 \mu \mathrm{M}$ epibrassinolide, confirming that this plant regulator promotes stomata formation in the hypocotyl (Table 1). The position of stomata relative to cortical tissue did not seem to change with growth conditions, as stomata developed in files overlying two cortical cell files (Table 1).

Two mutants, brassinosteroid insensitive1 (bri1) and deetiolated2 (det2), which were affected in the perception and synthesis of brassinosteroids, respectively (Li et al., 1996; Wang et al., 2001),

TABLE 1

NUMBER OF STOMATA IN THE HYPOCOTYL OF WILD-TYPE AND MUTANT SEEDLINGS GROWN UNDER DIFFERENT CONDITIONS

\begin{tabular}{|c|c|c|c|c|c|c|c|c|}
\hline & Col-0 & Ws-2 & Col & $\begin{array}{c}\text { bri1-1 } \\
\text { (in Col-0) }\end{array}$ & $\begin{array}{c}\text { bri1-4 } \\
\text { (in Ws-2) }\end{array}$ & $\begin{array}{c}\operatorname{det} 2-1 \\
\text { (in } \mathrm{Col} \text { ) }\end{array}$ & $\begin{array}{c}\text { pBRI1:BRI1:GFP } \\
\text { (in bri1-1) }\end{array}$ & $\begin{array}{c}\text { pBRI1:BRI1:GFP } \\
\text { (in bri1-4) }\end{array}$ \\
\hline Medium & $\begin{array}{c}19.0 \pm 5.6 \\
(93.3)\end{array}$ & $\begin{array}{c}30.0 \pm 5.4 \\
(93.3)\end{array}$ & $\begin{array}{c}17.0 \pm 3.7 \\
(93.5)\end{array}$ & $\begin{array}{c}2.0 \pm 1.4^{\mathrm{a}} \\
(92.2)\end{array}$ & $0.0 \pm 0.0^{\mathrm{a}}$ & $\begin{array}{c}9.0 \pm 4.1^{\mathrm{a}} \\
(93.3)\end{array}$ & $\begin{array}{c}19.8 \pm 4.7 \\
(93.3)\end{array}$ & $\begin{array}{l}29.4 \pm 5.3 \\
(92.2)\end{array}$ \\
\hline Medium + BL $(0.5 \mu \mathrm{M})$ & $\begin{array}{l}41.0 \pm 9.3^{\mathrm{b}} \\
(93.3)\end{array}$ & $\begin{array}{l}40.0 \pm 9.0^{\mathrm{b}} \\
(100)\end{array}$ & $\begin{array}{c}25.6 \pm 5.7^{b} \\
(93.3)\end{array}$ & $\begin{array}{c}2.0 \pm 1.8^{\mathrm{a}} \\
(93.5)\end{array}$ & $0.0 \pm 0.0^{\mathrm{a}}$ & $\begin{array}{c}23.0 \pm 9.9^{\mathrm{ab}} \\
(88.3)\end{array}$ & $\begin{array}{c}39.7 \pm 5.9^{b} \\
(93.3)\end{array}$ & $\begin{array}{l}40.5 \pm 5.1^{\mathrm{b}} \\
(93.3)\end{array}$ \\
\hline Medium + TAF $(1 \mu \mathrm{M})$ & $\begin{array}{c}20.0 \pm 5.7 \\
(88.3)\end{array}$ & $\begin{array}{l}23.0 \pm 6.2^{b} \\
(100)\end{array}$ & $\begin{array}{c}11.0 \pm 4.6^{\mathrm{b}} \\
(92.2)\end{array}$ & $\begin{array}{c}2.0 \pm 1.6^{\mathrm{a}} \\
(93.5)\end{array}$ & $0.0 \pm 0.0^{\mathrm{a}}$ & $\begin{array}{c}8.0 \pm 3.2^{\mathrm{a}} \\
(88.3)\end{array}$ & $\begin{array}{c}18.3 \pm 3.7 \\
(92.2)\end{array}$ & $\begin{array}{c}25.8 \pm 4.6 \\
(93.3)\end{array}$ \\
\hline Medium + BL $(0.5 \mu \mathrm{M})+\mathrm{TAF}(1 \mu \mathrm{M})$ & $\begin{array}{c}38.7 \pm 6.7^{\mathrm{b}} \\
(93.3)\end{array}$ & $\begin{array}{c}37.0 \pm 7.6^{\mathrm{b}} \\
(93.3)\end{array}$ & $\begin{array}{c}25.3 \pm 5.8^{b} \\
(93.5)\end{array}$ & $\begin{array}{c}3.0 \pm 2.3^{\mathrm{a}} \\
(93.5)\end{array}$ & $0.0 \pm 0.0^{\mathrm{a}}$ & $\begin{array}{c}27.0 \pm 8.9^{\mathrm{ab}} \\
(88.3)\end{array}$ & $\begin{array}{c}39.9 \pm 3.1^{\mathrm{b}} \\
(88.3)\end{array}$ & $\begin{array}{c}37.5 \pm 4.1^{\mathrm{b}} \\
(93.5)\end{array}$ \\
\hline
\end{tabular}

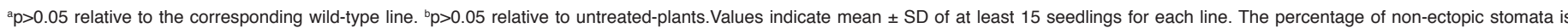
indicated between brackets. BL, epibrassinolide; TAF, triadimefon. 
were chosen for further characterization of brassinosteroid effects on stomatal production in the hypocotyl. Seedlings with null $B R 1$ mutations did not develop stomata (bri1-4) or develop an insignificant number of them (bri1-1), and those with DET2 mutations (det2-1) displayed a strong reduction in the number of stomata in comparison to untreated wild-type plants (Table 1). As expected, both bri1-1 and bri1-4 mutants showed absolute insensitivity to the different treatments, whereas det2-1 exhibited an increase in the number of stomata in response to the application of exogenous epibrassinolide (Table 1). The fact that both bri1-1/bri1-4 mutations block stomatal production but triadimefon only reduces it (Table 1), might suggest that brassinosteroids-regulated determinants of cell fate specification in the hypocotyl epidermis are active during embryogenesis.

In all the mutants, the position of the stomata relative to the cortical tissue was similar to that of wild-type plants (Table 1). As in wild-type seedlings, stomata of these mutants were located in the upper $2 / 3$ of the hypocotyl. Plants with the translation fusion consisting of a GFP-tagged $B R / 1$ construct driven by the $1.7 \mathrm{~kb}$ $B R / 1$ upstream region ( $p B R / 1: B R / 1: G F P$; Friedrichsen et al., 2000) were crossed into the bri1-1 and bri1-4 mutants, which rescued the defects induced by the mutations (Table 1). Taken together, these results show that, as expected, both $B R I 1$ and $D E T 2$ promote stomata formation in the hypocotyl.

\section{Brassinosteroids accelerate stomatal formation}

TMM is expressed in stomatal precursors and in younger neighbour cells (Nadeau and Sack, 2002). Thus, TTM expression can be used to identify the level of maturity of the stomata. Three levels of maturity were established: 1 ) mature stomata (without TMMexpression);2) stomata close to maturity (TMMexpression in with $0.5 \mu \mathrm{M}$ epibrassinolide exhibited elongated hypocotyls (Fig. $2 \mathrm{C})$. These results support that brassinosteroids promote stomatal pathway initiation, and that $T M M$ is required for meristemoids progression. Consistent with these results, bri1-1, bri1-4, det2-1 mutants and triadimefon-treated wild type plants have not arrested meristemoids like those found in tmm-1 mutant.

\section{Brassinosteroids control GL2 and CPC expression}

The hypothetical effect of brassinosteroids on expression of genes in the MYBs-TTG-BHLHs-GL2 network was determined. The expression of two genes in this network with opposite functions was studied: GL2, a repressor of stomatal development (Berger et al., 1998; Hung et al., 1998), and CPC, a positive regulator of this process (Serna, 2008). In wild-type plants harbouring the GL2:GUS construct, GUS activity has been preferentially detected in the upper portion of non-stomata-forming cell files (Hung et al., 1998). The pattern of GFP expression under the control of the GL2 promoter in plants grown in the presence of $0.5 \mu \mathrm{M}$ epibrassinolide (Fig. 3B) was indistinguishable from that of untreated control plants (Fig. 3A). However, the application of $1 \mu \mathrm{M}$ triadimefon disrupted the position-dependent pattern of GFP expression, leading to a largely random epidermal pattern of expression, with cells in both stomatal forming cell files and non-stomatal forming ones showing GFP expression (Fig. 3C). Co-application of $0.5 \mu$ M epibrassinolide triggered a GFPexpression pattern similar to that of untreated plants (Fig. 3D), confirming that the random epidermal pattern of expression is due to inhibition of the synthesis of brassinosteroids and not gibberellins. Taken together, these results indicate that brassinosteroids both prevent GL2 promoter induction in stomata-forming cell files and promote it in non-stomata forming ones. guard cells); and 3) young stomata (TMM expression in guard cells and in at least one neighbour cell) (Fig. $1 \mathrm{~A}-\mathrm{C}$ ). When plants were grown in the presence of $0.5 \mu \mathrm{M}$ epibrassinolide, the number of mature stomata (and those close to maturity) in the developing hypocotyl increased relative to that of untreated plants (Fig. 1D). Plants treated with 1 $\mu \mathrm{M}$ triadimefon exhibited a reduction in numbers of both fully developed stomata and stomata closer to maturity (Fig. 1D). This reduction was counteracted by co-application of $0.5 \mu \mathrm{M}$ epibrassinolide (Fig. 1D). These results indicate that brassinosteroids, in addition to promoting stomatal formation, accelerate stomatal development.

\section{Brassinosteroids do not reverse the lack of stomata in the tmm-1 hypocotyl}

The tmm hypocotyl has virtually no stomata, but arrested meristemoids (Bhave et al., 2009). To determine whether brassinosteroids suppress this tmm dependent defect, $t m m-1$ seedlings were grown on media supplemented with $0.5 \mu \mathrm{M}$ epibrassinolide. The phytohormone, at a concentration of $0.5 \mu \mathrm{M}$, was able to induce stomatal production in wild-type plants (Fig. 2A). The tmm-1 mutant treated in this manner did not develop stomata, but it increased its number of meristemoids (Fig. 2B). Both wild-type and $t m m-1$ seedlings treated
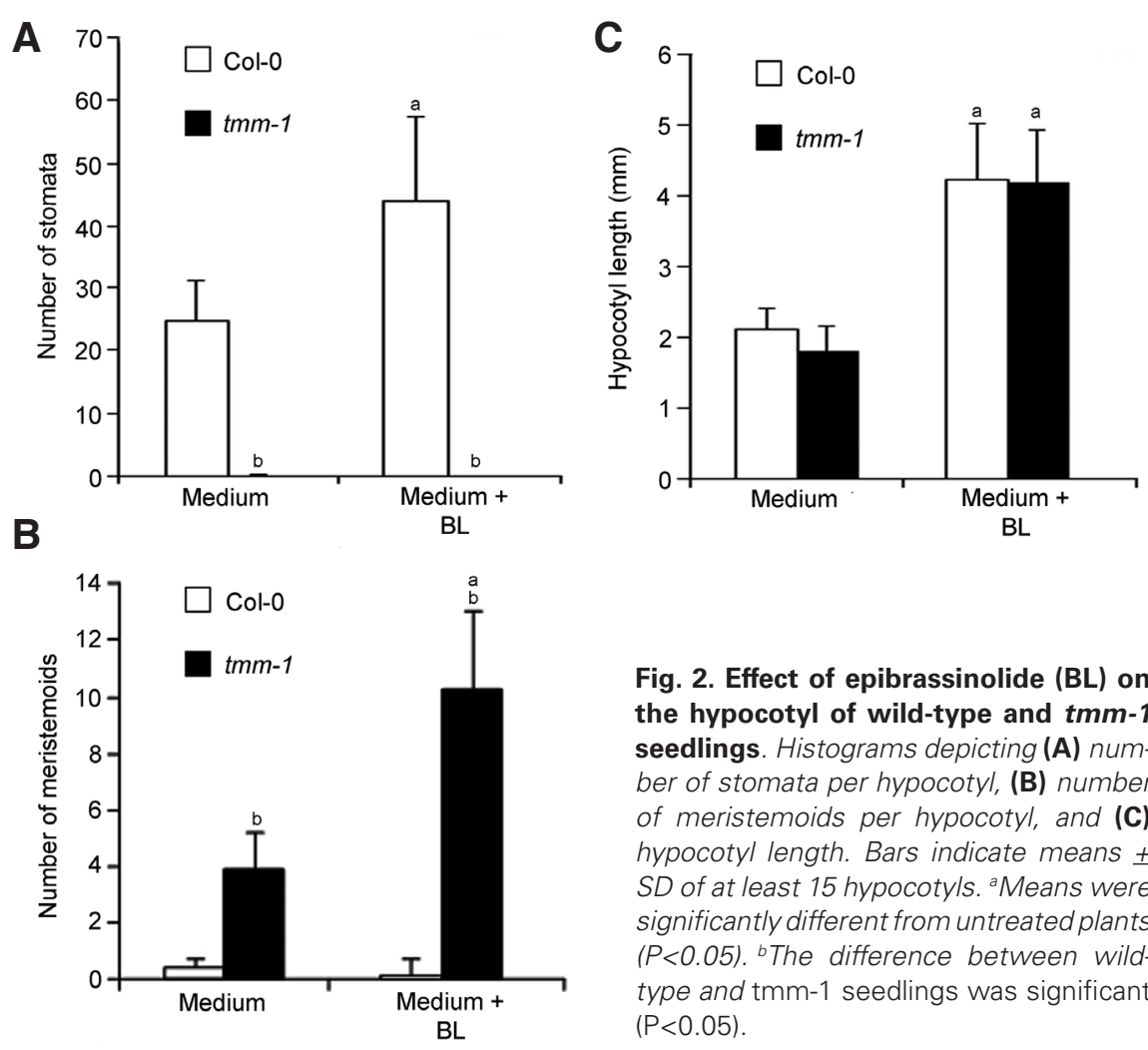

Fig. 2. Effect of epibrassinolide (BL) on the hypocotyl of wild-type and tmm-1 seedlings. Histograms depicting (A) number of stomata per hypocotyl, (B) number of meristemoids per hypocotyl, and (C) hypocotyl length. Bars indicate means \pm $S D$ of at least 15 hypocotyls. ${ }^{a}$ Means were significantly different from untreated plants $(P<0.05){ }^{b}$ The difference between wildtype and tmm-1 seedlings was significant $(\mathrm{P}<0.05)$. 
CONTROL

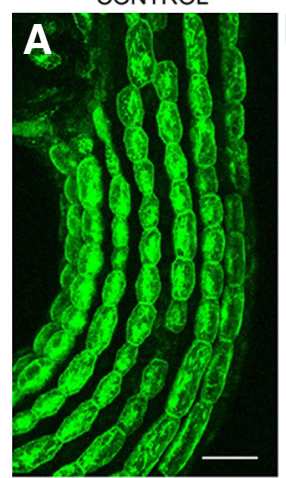

CONTROL

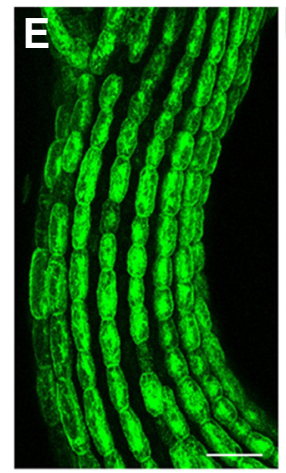

$\mathrm{BL}$

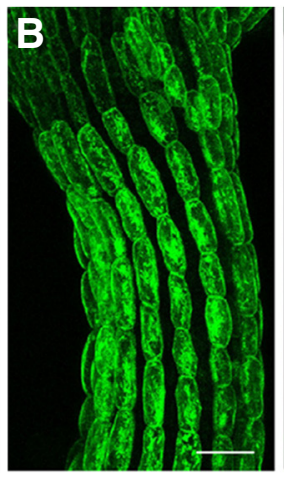

$\mathrm{BL}$

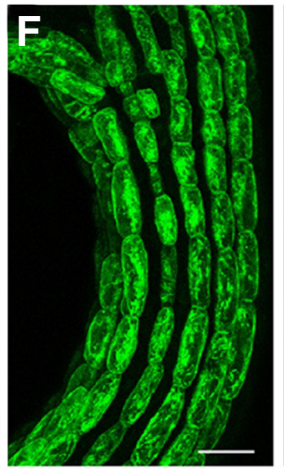

TAF

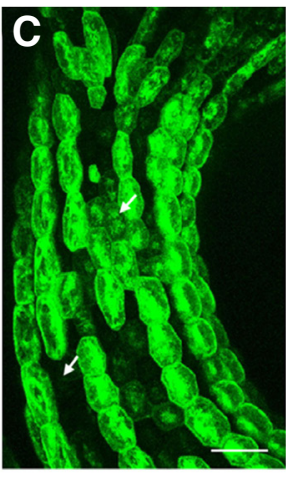

TAF

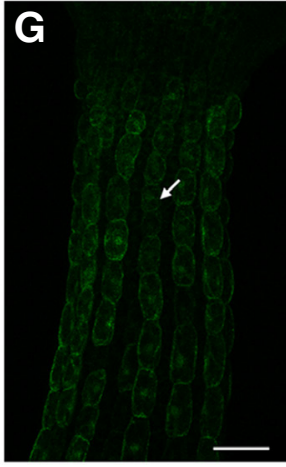

$B L+T A F$

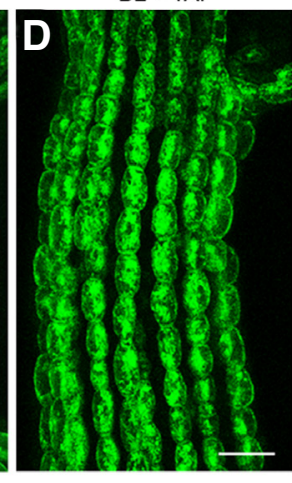

$\mathrm{BL}+\mathrm{TAF}$

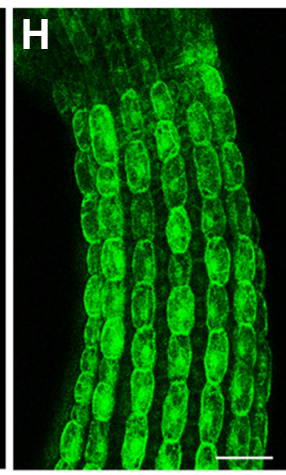

Fig. 3. Brassinosteroid effect on both $G L 2$ and $C P C$ promoter induction in the hypocotyl epidermis. (A-D) Pattern of GFP expression driven by the GL2 promoter. (E-H) Expression of GFP under the control of the CPC promoter. (C) Random GL2:GFP expression and (G) strong reduction of CPC:GFP expression is indicated by arrows. BL, epibrassinolide; TAF, triadimefon. Scale bars: $150 \mu \mathrm{m}$ in $(\mathrm{A}-\mathrm{H})$.

triadimefon (Table 2). The number of stomata of g/2-1 in all growth conditions, with the exception of mediums supplemented with both epibrassinolide and triadimefon, was higher than that of wild-type seedlings given its particular ability to produce ectopic stomata (Table 2).

$C P C$ also controls stomata formation in the embryonic stem, with the $c p c$ mutant displaying a reduced number of stomata in comparison to wildtype seedlings (Serna, 2008; Table 2). Interestingly, the $c p c$ mutant increased stomatal production in response to epibrassinolide (Table 2). However, try $c p c$ had a low number of stomata under all growth conditions showing absolute insensitivity to the different treatments (Table 2). The triple mutant try $c p c$ det2-1 phenocopied the very low number of stomata of try $c p c$ (Table 2). In addition, it also exhibited insensitivity to the phytohormone brassinosteroid, almost blocking stomatal formation

GUS activity, in plants harbouring the CPC:GUS construct, has also been preferentially detected in non-stomata-forming cell files (Kirik et al., 2004; Serna, 2008). In plants grown in the presence of $0.5 \mu \mathrm{M}$ epibrassinolide, CPC:GFP expression was identical to that of untreated plants (Fig. $3 \mathrm{E}, \mathrm{F}$ ). A strong reduction of $C P C$ :GFP expression was observed in plants treated with $1 \mu \mathrm{M}$ triadimefon (Fig. $3 \mathrm{G}$ ), which was restored by co-application of $0.5 \mu \mathrm{M}$ epibrassinolide (Fig. $3 \mathrm{H})$. These results indicate that brassinosteroids positively regulate $C P C$ promoter induction in non-stomata-forming cell files.

\section{Brassinosteroids do not reverse the low number of stomata in the try cpc hypocotyl}

The gl2 mutation ( $g / 2-1)$ increases the number of stomata, with many of them being located in epidermal files overlying a single cortical cell file (Berger et al., 1998; Table 2). The gl2-1 mutant responded to the treatments, increasing stomatal production in response to brassinosteroids and decreasing it in response to under all growth conditions (Table 2).

\section{Discussion}

The responses of bri1-1, bri1-4 and det2-1 mutants to brassinosteroids are consistent with the general effect of these phytohormones to promote stomatal production in the hypocotyl. Both bri1-1 and bri1-4 mutants showed absolute insensitivity to the various treatments and det2-1 had elevated numbers of stomata in response to epibrassinolide. Consistent with these results, the number of stomata in the hypocotyls of bri1-116, $c p d$ (unable to synthesize brassinosteroids) and of the gain-of function mutant bin2-1 (BIN2 represses brassinosteroids signalling) was strongly reduced, and this number was increased in bin2-3 atsk22 atsk23, bin2-3 (ATSK22, ATSK23 and BIN2 act in a redundant manner) and in plants overexpressing the brassinosteroid biosynthetic gene DWARF4 (Gudesblat et al., 2012). Interestingly, mutations

TABLE 2

NUMBER OF STOMATA IN THE HYPOCOTYL OF WILD-TYPE AND MUTANT SEEDLINGS GROWN GROWN UNDER DIFFERENT CONDITIONS

\begin{tabular}{|c|c|c|c|c|c|c|}
\hline & Ws-2 & Ler & $\begin{array}{c}c p c \\
\text { (in Ws-2) }\end{array}$ & $\begin{array}{l}\text { try cpc } \\
\text { (in Ler) }\end{array}$ & $\begin{array}{c}g / 2-1 \\
\text { (in Ler) }\end{array}$ & $\begin{array}{c}\text { det2-1 } \\
\text { try cpc }\end{array}$ \\
\hline Medium & $30.0 \pm 5.4(93.3)$ & $19.0 \pm 5.1(96.7)$ & $14.0 \pm 2.3^{\mathrm{a}}(93.3)$ & $\begin{array}{c}1.0 \pm 2.8^{a} \\
(90.0)\end{array}$ & $32.0 \pm 8.4^{\mathrm{a}}(73.3)$ & $\begin{array}{c}1.0 \pm 2.9 \\
(89.5)\end{array}$ \\
\hline Medium + BL $(0.5 \mu \mathrm{M})$ & $40.0 \pm 9.0^{\mathrm{b}}(100)$ & $34.0 \pm 7.3^{\mathrm{b}}(93.3)$ & $25.0 \pm 9.0^{\mathrm{ab}}(90.0)$ & $\begin{array}{c}2.0 \pm 4.1^{\mathrm{a}} \\
(89.5)\end{array}$ & $47.0 \pm 10.0^{\mathrm{ab}}(70.0)$ & $\begin{array}{c}2.0 \pm 4.3 \\
(90.0)\end{array}$ \\
\hline Medium + TAF $(1 \mu \mathrm{M})$ & $23.0 \pm 6.2^{\mathrm{b}}(100)$ & $13.0 \pm 5.5^{\mathrm{b}}(100)$ & $14.0 \pm 4.0^{\mathrm{a}}(90.0)$ & $\begin{array}{c}2.0 \pm 4.3^{\mathrm{a}} \\
(90.0)\end{array}$ & $23.0 \pm 6.7^{\mathrm{ab}}(76.7)$ & $\begin{array}{c}1.0 \pm 2.8 \\
(90.0)\end{array}$ \\
\hline Medium + BL $(0.5 \mu \mathrm{M})+\mathrm{TAF}(1 \mu \mathrm{M})$ & $37.0 \pm 7.6^{\mathrm{b}}(93.3)$ & $37.0 \pm 6.1^{\mathrm{b}}(96.7)$ & $29.0 \pm 8.7^{\mathrm{ab}}(90.0)$ & $\begin{array}{c}1.0 \pm 2.9^{\mathrm{a}} \\
(94.1)\end{array}$ & $\begin{array}{c}32.0 \pm 6.1 \\
(63.4)\end{array}$ & $\begin{array}{c}1.0 \pm 2.9 \\
(93.3)\end{array}$ \\
\hline
\end{tabular}

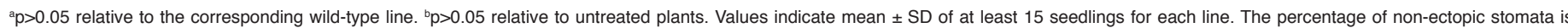
indicated between brackets. BL, epibrassinolide; TAF, triadimefon. 
in the downstream targets of $B I N 2, B Z R$ and $B E S 1$, do not disrupt stomatal formation in the hypocotyl, suggesting that BIN2 control stomatal development by regulation of other targets (Gudesblat et al., 2012). In addition, the brassinosteroid-insensitive quadruple mutant bsu-q exhibits stomatal clusters (Kim et al., 2012).

Epibrassinolide did not reverse the lack of stomata in the tmm1 hypocotyl, but it increased the number of meristemoids, which supports that brassinosteroids promote stomata pathway initiation, and $T M M$ is required in later stages for meristemoids progression. TMM signalling cascade leads to SPCH inactivation, which is required for early stages of stomatal development (Pillitteri and Torii, 2012). The fact that epibrassinolide increases meristemoids production in tmm-1, indicates that these plant regulators do not play upstream of TMM regulating stomatal initiation.

Hormone tests, reporter gene studies, and mutant analyses have increased our understanding of the potential interactions between brassinosteroids and the MYBs-BHLHs-TTG-GL2 network during stomatal formation in the hypocotyl. Supplementing medium with epibrassinolide did not affect the GL2 promoter induction pattern (in which the GL2promoter is preferentially induced in non-stomata forming cell files) or the stomatal pattern (in which most stomata are located in files overlying two cortical cell files). However, growth of plants in the presence of triadimefon resulted in a random GL2 promoter induction and in a reduction in the number of stomata. Similar to the GL2 promoter, the CPC promoter pattern did not change when plants were grown in the presence of epibrassinolide. However, triadimefon reduced CPC promoter induction, which agrees with the insensitivity to the inhibitor displayed by the $c p c$ mutant. These results suggest that inhibition of brassinosteroids synthesis represses stomata formation in part by repressing CPC expression. Genetic redundancy between TRY and $C P C$, which show high sequence similarity, might explain the sensitivity of the $c p c$ mutant to epibrassinolide. Consistent with this inference, try $c p c$ did not respond to the phytohormone. Interestingly, g/2-1 responded to the treatments, suggesting that other genes might be masking this absence of $g$ l2-1 response. The fact that the triple mutant try cpc det2-1 phenocopied the near absence of stomata of try $c p c$, exhibiting also insensitivity to the phytohormone, supports that brassinosteroids act upstream of $C P C$ and TRY. These results suggest that brassinosteroids control stomatal cell fate through regulation of both GL2 and CPC expression. In contrast to our interpretation, and based on the number of cells per file, Gudesblat et al., (2012) have just proposed that brassinosteroids do not affect cell fate in the hypocotyl epidermis. It is then likely that brassinosteroids act a two different levels on stomatal development in the hypocotyl. On one hand, brassinosteroids regulate the repressive cascade that inactivates the transcriptional factor SPCH necessary for stomata formation (Gudesblat et al., 2012). On the other, they control cell patterning specification through the regulation of the expression of genes playing in the MYBs-TTGBHLHs-GL2 network. How these two networks might interact is an open question.

Similar to stomata, root hairs develop in files located outside two cortical cell files (Dolan et al., 1993; Dolan et al., 1994; Galway et al., 1994). In addition, a number of experimental studies have shown that the same MYBs-BHLHs-TTG-GL2 network controls epidermal cell fate in both organs (Larkin et al., 2003; Schiefelbein et al., 2003; Serna 2004a; Serna, 2004b). In roots, brassinosteroids also promote root hair formation, acting upstream of the MYBs-BHLHs-TTG-GL2 network (Kuppusamy et al., 2009). Similar to what occurs in the hypocotyl epidermis, the loss of brassinosteroid signalling in the root results in random patterns of GL2 expression and in a strong reduction of CPC expression (Kuppusamy et al., 2009). The MYBsBHLHs-TTG-GL2 network does not seem to play a role in stomata formation in the cotyledon (and leaf) as suggested by the fact that mutations in TTG or GL2 do not induce an apparent phenotype (Berger et al., 1998). However, brassinosteroids control stomatal production in cotyledons and leaves (Gudesblat et al., 2012; Kim et al., 2012), although their specific role need clarification. Genetic and biochemical analyses have demonstrated that these plant regulators inhibit stomatal development in the cotyledons through the GSK3-like BIN2 kinase, which phosphorylates and inactivates the stomatal MAPK kinase kinase YDA, acting downstream of the ERECTA family of receptor-like kinases and of the receptor protein TMM (Kim et al., 2012). In contrast to these results, Gudesblat et al., (2012) have shown that brassinosteroids promote stomatal formation in the leaves and cotyledons by inhibition of BIN2mediated phosphorilation of $\mathrm{SPCH}$. What seems certain is that while the genetic control of the production of stomata in the leaves (or cotyledons) differs from that of the hypocotyl, brassinosteroids control the stomatal formation in both organs.

\section{Materials and Methods}

\section{Plant material and growth conditions}

Mutants and transgenic plants used in this work included bri1-1 (N3723), bri1-4 (N3953), det2-1 (N6159), tmm-1 (N6140), gl2-1 (N65), cpc, try cpc, GL2:GFP(N8851), CPC:GFP, TMM:GUS:GFP, and pBRI1:BRI1:GFP. The wild-type strains included Wassilewskija (Ws-2), Columbia (Col), Columbia (Col-0) and Landsberg erecta (Ler).

Seeds were vernalized at $4^{\circ} \mathrm{C}$ for several days and surface-sterilized in $5 \%$ sodium hypochlorite. They were sown on $1 \%$ agar-solidified medium containing Murashige and Skoog salts (Sigma) and 1\% sucrose with or without epibrassinolide and/or triadimefon. Seedlings were germinated and grown on horizontally oriented dishes at $22^{\circ}$ in light (16-hours-light/8hours-dark cycle).

\section{Characterization of epidermal features}

To determine the total number of stomata (or meristemoids) per hypocotyl, 2-week-old seedlings were mounted on slides, examined, and digitized under Nomarsky optics. Localization of stomatal cells relative to underlying cortical cells was determined from two randomly selected stomata per hypocotyl (15 seedlings) by focusing alternatively on both epidermal and cortical focal planes. Stomata in epidermal files making contact with a single cortical cell file were defined as ectopics and those in files that contact two cortical cell files as non-ectopics (Berger et al., 1998; Hung et al., 1998).

\section{GUS staining}

For histochemical analysis of GUS expression, 3-day-old seedlings harbouring the transgenes were assayed for GUS activity as previously described (Jefferson et al., 1987). After histochemical GUS assays, seedlings were washed in graded ethanol to remove chlorophyll and enhance contrast. All samples were examined by light microscopy with a Leica DC 300F camera attached to a Leica MZ6 stereomicroscope and to a Leica DMIRB inverted microscope. Images were acquired with the Leica Application Suite and processed with Adobe Photoshop CS3 (Adobe).

\section{GFP imaging}

GFP fluorescence from 3-day-old seedlings was monitorized with a DMIRB inverted Leica TCS SP2 confocal microscope using a $488 \mathrm{~nm}$ laser line of an Argon laser. For visualization of GFP, the emission window was set at 500-525 nm. GFP fluorescence was performed using a 40x/NA 
1.25-0.75 PL APO (oil immersion) objective. Images were recorded with picture size of $1024 \times 1024$ pixels. They were arranged and labelled using Adobe Photoshop 6.0.

\section{Acknowledgements}

We thank J. Chory for kindly providing pBRI1:BRI1:GFP transgenic plants, Liam Dolan for the CPC:GFP and GL2:GFP plants, J. Nadeau for the TMM:GUS:GFP line, and M. Hülskamp for the try and try срс mutants. This work was supported by grants from the Communities Council of Castilla-La Mancha (PCI08-0041-1136) and the Ministry of Education and Culture of Spain (BIO2008-02149). RCC and SF were supported by Communities Council of Castilla-La Mancha fellowships.

\section{References}

ASAMI, T., MIZUTANI, M., SHIMADA, Y., GODA, H., KITAHATA, N., SEKIMATA, K., HAN, S.-Y., FUJIOKA, S., TAKATSUTO, S., SAKATA, K. and YOSHIDAS. (2003). Triadimefon, a fungicidal triazole-type P450 inhibitor, induces brassinosteroid deficiency-like phenotypes in plants and binds to DWF4 protein in the brassinosteroid biosynthesis pathway. Biochemical J. 369: 71-76.

BERGER, F., LINSTEAD, P., DOLAN, L. and HASELOFF, J. (1998). Stomata patterning on the hypocotyl of Arabidopsis thaliana is controlled by genes involved in the control of root epidermis patterning. Dev. Biol. 194: 226-234.

BERNHARDT, C., LEE, M.M., GONZALEZ, A., ZHANG, F., LLOYD, A. and SCHIEFELBEIN, J. (2003). The bHLH genes GLABRA3 (GL3) and ENHANCER OF GLABRA3 (EGL3) specify epidermal cell fate in the Arabidopsis root. Development 130: 6431-6419.

BERNHARDT, C., ZHAO, M., GONZALEZ, A., LLOYD, A. and SCHIEFELBEIN, J. (2005). The bHLH genes GL3 and EGL3 participate in an intercellular regulatory circuit that controls cell patterning in the Arabidopsis root epidermis. Development 132: 291-298.

BHAVE, N.S., VELEY, K.M., NADEAU, J.A., LUCAS, J.R., BHAVE, S.L. and SACK, F.D. (2009). TOO MANY MOUTHS promotes cell fate progression in stomatal development of Arabidopsis stems. Planta 229: 357-367.

BUCHENAUER, H. and ROHNER, E. (1981). Effect of triadimefon and triadimenol on growth of various plant species as well as on gibberellin content and sterol metabolism in shoots of barley seedlings. Pest. Biochem. Physiol. 15: 58-70.

DI CRISTINA, M.D., SESSA, G., DOLAN, L., LINSTEAD, P., BAIMA, S., RUBERTI, I. and MORELLI, G. (1996). The Arabidopsis Athb-10 (GLABRA2) is an HD-Zip protein required for regulation of root hair development. Plant J. 10: 393-402.

DOLAN, L., JANMAAT, K., WILLEMSEN, V., LINSTEAD, P., POETHIG, S., ROBERTS, K. and SCHERES, B. (1993). Cellular organisation of the Arabidopsis thaliana root. Development 119: 71-84.

DOLAN, L., DUCKETT, C.M., GRIERSON, C., LINSTEAD, P., SCHNEIDER, K., LAWSON, E., DEAN, C., POETHIG, S. and ROBERTS, K. (1994). Clonal relationships and cell patterning in the root epidermis of Arabidopsis. Development 120: $2465-2474$.

FRIEDRICHSEN, D.M., JOAZEIRO, C.A.P., JIANMING, L., HUNTER, T. and CHORY, J. (2000). Brassinosteroid-insensitive-1 is a ubiquitously expressed leucine-rich repeat receptor serine/threonine kinase. Plant Physiol. 123: 1247-1255.

GALWAY, M.E., MASUCCI, J.D., LLOYD, A.M., WALBOT, V., DAVIS, R.W. and SCHIEFELBEIN, J.W. (1994). The TTG gene is required to specify epidermal cell fate and cell patterning in the Arabidopsis root. Dev. Biol. 166: 740-754.

GEISLER, M., YANG, M. and SACK, F.D. (1998). Divergent regulation of stomatal initiation and patterning in organ and suborgan regions of the Arabidopsis mutants too many mouths and four lips. Planta 205: 522-530.

GENDREAU, E., TRAAS, J., DESNOS, T., GRANDJEAN, O., CABOCHE, M. and HÖFTE, H. (1997). Cellular basis of hypocotyl growth in Arabidopsis thaliana. Plant Physiol. 114: 295-305.

GUDESBLAT, G.E., SCHNEIDER-PIZÓN, J., BETTI, C., MAYERHOFER, J., VANHOUTTE, I., VAN DONGEN, W., BOEREN, S., ZHIPONOVA, M., DE VRIES, S., JONAK, C. and RUSSINOVA, E. (2012). SPEECHLESS integrates brassinosteroid and stomata signalling pathways. Nat. Cell Biol. 14: 548-554.

HUNG, C.-Y., LIN, Y., ZHANG, M., POLLOCK, S., MARKS, M.D. and SCHIEFELBEIN, J. (1998). A common position-dependent mechanism controls cell-type patterning and GLABRA2 regulation in the root and hypocotyl epidermis of Arabidopsis. Plant Physiol. 117: 73-84.

JEFFERSON, R.A., KAVANAGH, T.A. and BEVAN, M.W. (1987). GUS fusions: $\beta$ Glucuronidase as a sensitive and versatile gene fusions marker in higher plants. EMBO J. 6: 3901-3907.

KIM, T.-W., MICHNIEWICZ, M., BERGMANN, D.C. and WANG, Z.-Y. (2012). Brassinosteroid regulates stomatal development by GSK3-mediated inhibition of a MAPK pathway. Nature 482: 419-422.

KIRIK, V., SIMON, M., HUELSKAMP, M. and SCHIEFELBEIN J. (2004). The ENHANCER OF TRY AND CPC1gene acts redundantly with TRIPTYCHON and CAPRICE in trichome and root hair cell patterning in Arabidopsis. Dev. Biol. 268: 506-513.

KUPPUSAMY, K.T., CHEN, A. Y. and NEMHAUSER, J.L. (2009). Steroids are required for epidermal cell fate establishment in Arabidopsis roots. Proc. Natl. Acad. Sci. USA 106: 8073-8076.

LARKIN, J.C., BROWN, M.L. and SCHIEFELBEIN, J. (2003). How cells know what they want to be when they grow up? Lessons from epidermal patterning in Arabidopsis. Annu. Rev. Plant Biol. 54: 403-430.

LEE, M.M. and SCHIEFELBEIN, J. (1999). WEREWOLF, a MYB-related protein in Arabidopsis, is a position dependent regulator of epidermal cell patterning. Cell 99: 473-483.

LI J., NAGPAL, P., VITART, V., MCMORRIS, T.C. and CHORY, J. (1996). A role for brassinosteroids in light-dependent development of Arabidopsis. Science 272: 398-401.

NADEAU, J.A. and SACK, F.D. (2002). Control of stomatal distribution on the Arabidopsis leaf surface. Science 296: 1697-1700.

NEMHAUSER, J.L., MOCKLER, T.C. and CHORY, J. (2004). Interdependency of Brassinosteroid and Auxin Signaling in Arabidopsis. PLoS Biol. 2(9): e258.

PAYNE, C.T., ZHANG, F. and LLOYD, A.M. (2000). GL3encodes a bHLH protein that regulates trichome development in Arabidopsis through interaction with $G L 1$ and TTG1. Genetics 156: 1349-1362.

PILLITTERI, L.J. and TORII, K.U. (2012). Mechanisms of stomatal development. Annu. Rev. Plant Biol. 63: 12.1-12.24.

RERIE, W.G., FELDMANN, K.A. and MARKS, M.D. (1994). The GLABRA2 gene encodes a homeodomain protein required for normal trichome development in Arabidopsis. Genes Dev. 8: 1388-1399.

SAIBO, N.J., VRIEZEN, W.H., BEEMSTER, G.T. and VAN DER STRAETEN, D. (2003). Growth and stomata development of Arabidopsis hypocotyls are controlled by gibberellins and modulated by ethylene and auxins. Plant J. 33: 989-1000.

SCHELLMANN, S., SCHNITTGER, A., KIRIK, V., WADA, T., OKADA, K., BEERMANN, A., THUMFAHRT, J., JÜRGENS, G. and HÜLSKAMP, M. (2002). TRIPTYCHON and CAPRICE mediate lateral inhibition during trichome and root hair patterning in Arabidopsis. EMBO J. 21: 5036-5046.

SCHIEFELBEIN, J. (2003). Cell-fate specification in the epidermis: a common patterning mechanism in the root and shoot. Curr. Opin. Plant Biol. 6: 74-78.

SERNA, L. (2004a). Epidermal cell patterning and differentiation throughout the apical-basal axis of the seedling. J. Exp. Bot. 56: 1983-1989.

SERNA, L. (2004b). A network of interacting factors triggering different cell fates. Plant Cell 16: 2258-2263.

SERNA, L. (2008). CAPRICE positively regulates stomatal formation in the Arabidopsis hypocotyl. Plant Sig. Behav. 3: 1-6.

WADA, T., TACHIBANA, T., SHIMURA, Y. and OKADA, K. (1997). Epidermal cell differentiation in Arabidopsis determined by a Myb homolog, CPC. Science 277: 1113-1116.

WALKER, A.R., DAVISON, P.A., BOLOGNESI-WINFIELD, A.C., JAMES, C.M., SRINIVASAN, N., BLUNDELL, T.L., ESCH, J.J., MARKS, M.D. and GRAY, J.C. (1999). The TRANSPARENT TESTA GLABRA1 locus, which regulates trichome differentiation and anthocyanin biosynthesis in Arabidopsis, encodes a WD40 repeat protein. Plant Cell 11: 1337-1349.

WANG, Z.-Y., SETO, H., FUJIOKA, S., YOSHIDA, S. and CHORY, J. (2001). BRI1 is a critical component of a plasma-membrane receptor for plant steroids. Nature 410: $380-383$

ZHANG, F., GONZALEZ, A., ZHAO, M., PAYNE, C.T. and LLOYD, A. (2003). A network of redundant bHLH proteins functions in all TTG1-dependent pathways of Arabidopsis. Development 130: 4859-4869. 


\section{Further Related Reading, published previously in the Int. J. Dev. Biol.}

Stomatal development in Arabidopsis and grasses: differences and commonalities Laura Serna

Int. J. Dev. Biol. (2011) 55: 5-10

Female gametophytic mutants of Arabidopsis thaliana identified in a gene trap insertional mutagenesis screen Vladimir B. Brukhin, Miloslawa Jaciubek, Arturo Bolaños Carpio, Vera Kuzmina and Ueli Grossniklaus Int. J. Dev. Biol. (2011) 55: 73-84

Instructive roles for hormones in plant development

David Alabadí, Miguel A. Blázquez, Juan Carbonell, Cristina Ferrándiz and Miguel A. PérezAmador

Int. J. Dev. Biol. (2009) 53: 1597-1608

Arabidopsis monomeric G-proteins, markers of early and late events in cell differentiation Mariette Bedhomme, Chantal Mathieu, Amada Pulido, Yves Henry and Catherine Bergounioux Int. J. Dev. Biol. (2009) 53: 177-185

Equivalent genetic regulatory networks in different contexts recover contrasting spatial cell patterns that resemble those in Arabidopsis root and leaf epidermis: a dynamic model Mariana Benítez, Carlos Espinosa-Soto, Pablo Padilla-Longoria, José Díaz and Elena R. Alvarez-Buylla

Int. J. Dev. Biol. (2007) 51: 139-155

ULTRACURVATA1, a SHAGGY-like Arabidopsis gene required for cell elongation JM Perez-Perez, MR Ponce, JL Micol

Int. J. Dev. Biol. (2001) 45: S51-S52

5 yr ISI Impact Factor $(2011)=2.959$
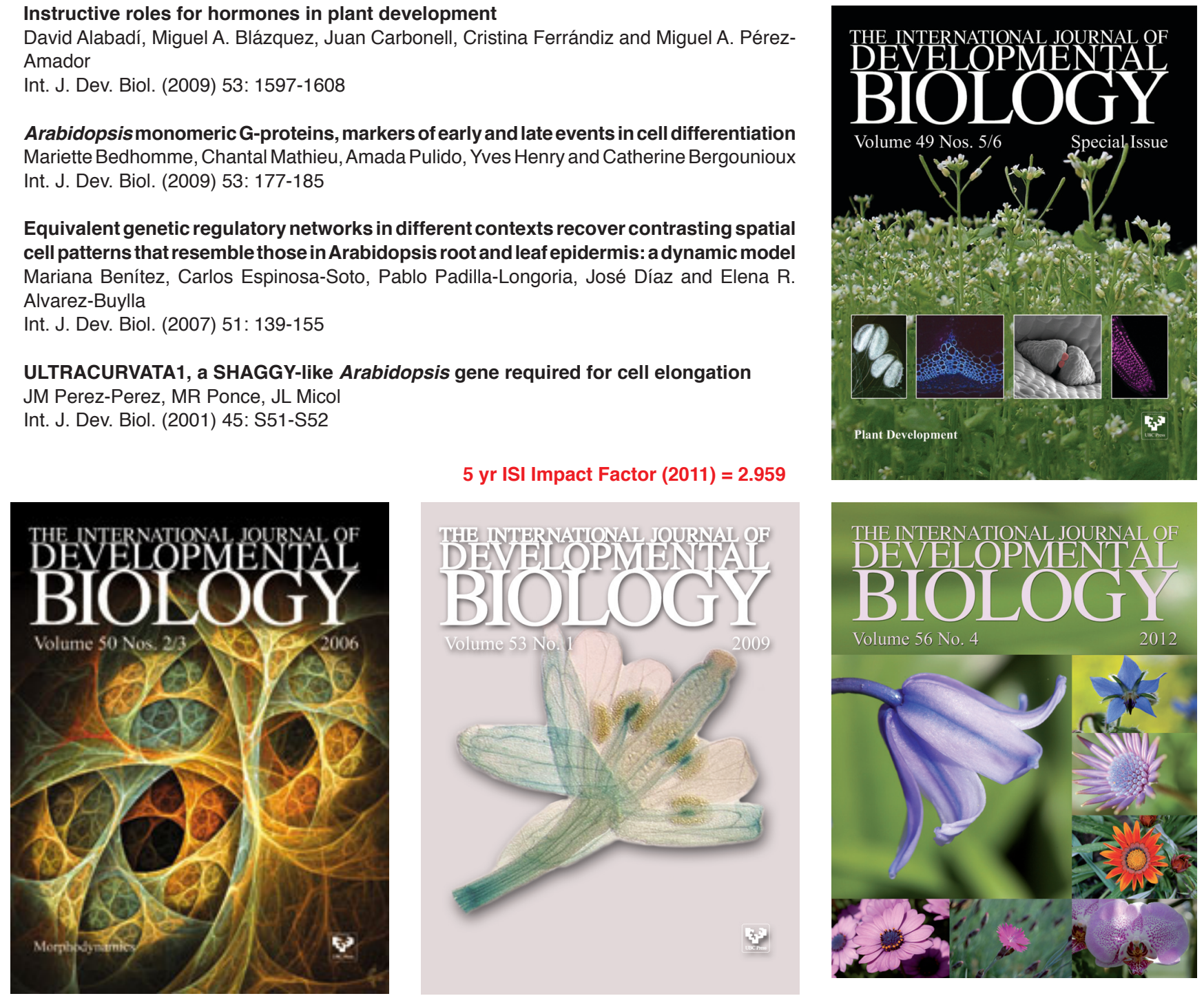